ROYAL AUSTRALIAN AND NEW ZEALAND COLLEGE OF PSYCHIATRISTS (2004) The Royal Australian and New Zealand College of Psychiatrists Equivalence Guidelines. http://www.ranzcp.org/pdffiles/ training/exempt/Equivalence\%20Table\% 20Revised\%20June\%202004.pdf

Varuni de Silva Senior Lecturer in Psychiatry, Faculty of Medicine, University of Colombo, Colombo, Sri Lanka

Professor Khan echoes a sentiment shared by hundreds of psychiatrists who have passed the MRCPsych exams after great deal of hard work; it is frustrating to see others who have never been through the process still get the MRCPsych. Dr Bhugra states that this 'College is the only Royal College which has tried to be inclusive'. By doing what - handing out Membership for free! This is certainly not something to be proud of. This is a mere gimmick to entice psychiatrists to work in the UK and in my view greatly lowers the credibility of the College.

I moved from the UK to work in the USA and it is very common to see psychiatrists who trained in the UK and have moved here. Psychiatrists still continue to come here from the UK, many even after passing the MRCPsych. One of the most common reasons cited is the inherent unfairness of a system where everything is based on need rather than on merit. In contrast becoming a Boardcertified psychiatrist in the USA involves passing the exams of the American Board of Psychiatry and Neurology after the required number of years of training. There are no exceptions based on fame, repute or need.

MRCPsych is an award I was proud to add after my name and despite moving to the USA, I have continued to pay my fees to the College. However, I no longer see any point in paying over $\mathrm{f300}$ a year for something that anyone can have and have decided to stop paying my annual Membership fees. However, since my fees are currently up to date, I continue to add MRCPsych after my name for the time being!

Maju Mathews Assistant Professor of Psychiatry, Drexel University College of Medicine, Philadelphia, Pennsylvania, USA,

e-mail:maju.mathews@drexelmed.edu

In his excellent article Professor Khan raises concerns regarding the awarding of Membership of the College without adequate checks. He points towards the College's high standing and its ability to guide opinion in countries which have not yet developed such structures for themselves. The British Medical Royal Colleges have traditionally had this role throughout those Commonwealth countries that have largely adopted a UK-style postgraduate education system and teach in English. This is an enormous responsibility and at the same time reason for the College's dilemma. The College is not merely the guardian of professional standards and education but also provides professional guidance beyond its own borders. This is further complicated by the fact that to get a job as a specialist a psychiatrist does not necessarily have to be a member of the College, so the College has no effective role in controlling access to work as a specialist. This latter point is in stark contrast to Royal Colleges or similar bodies across the European Union whose primary role it is to control access to specialist jobs. It is this complex role with no effective control function regarding access to jobs that causes the dilemma faced by our College and exacerbates the problems described by Professor Khan. The answer could be to subdivide the three roles of: (a) controlling access to specialist jobs; (b) controlling education; and (c) setting standards and giving professional guidance at home and abroad.

Peter Lepping Consultant Psychiatrist/Honorary Lecturer, University of Wales, Llwyn-y-groes Psychiatric Unit, Wrexham Maelor Hospital, Croesnewydd Road, Wrexham LL13 7TD, Wales, e-mail: peter.lepping@new-tr.wales.nhs.uk

I fully agree with the views expressed by Dr Khan and I appreciate the comments made by Professor Bhugra (Psychiatric Bulletin, January 2006, 30,3-6). It is heartening to note that the College is striving hard to maintain the highest standards of training and ethics and that certain steps are being taken to establish new guidelines and criteria to uphold these standards across the board. MRCPsych is undoubtedly the most prestigious qualification and therefore it should not be awarded to those who fail to meet its standards.

Professor Bhugra mentions two groups of people who could be awarded this qualification without examination. However, there is another group which he fails to mention. Under Article 14, the Postgraduate Medical and Education Training Board (PMETB) can now conside the applications of many middle grade doctors for specialist registration who do not have the accredited higher specialist training or who have previously been unsuccessful in the MRCPsych examination. If some of these applicants are successful, then they will move on to the specialist register of the General Medical Council, thereby automatically qualifying for Membership of the College.

I suggest that the College sets up a tier system whereby these potential awardees, before being granted Membership, either take some form of modular examination or undergo a series of training workshops and courses. By implementing such a system the College will be able to appraise the knowledge and skills of these doctors objectively. It will also enable these doctors to match the standards achieved by those who acquire MRCPsych through normal means If this is not possible then the College should seriously consider amending the Bye-Laws once again.

Rameez Zafar Consultant Psychiatrist, Peter Hodgkinson Centre, Lincoln LN2 5UA, e-mail: Rameez.Zafar@|pt.nhs.uk

am writing to express the view of the Collegiate Trainees' Committee (CTC) on the issue of Membership without examination as discussed at the last CTC meeting. Although acknowledging the importance of recognising senior psychiatrists of international repute, trainees are opposed to the idea of indiscriminate awarding of the MRCPsych to overseas psychiatrists if they have not passed the UK examinations.

There are two lines of reasoning supporting this argument. First, there seems to be a plethora of ways in many countries to obtain a postgraduate psychiatric qualification, one of the eligibility criteria for the awared of Membership without examination (Psychiatric Bulletin, January 2006, 30, 3-6). As some of these qualifications are not underpinned by training, assessment and quality-assurance systems as robust as those in the UK, awarding the reputable MRCPsych to holders of only these qualifications would seriously devalue the MRCPsych in the eyes of not only the medical community but also the public at large. Second, awarding the MRCPsych to those who have not toiled through a very rigorous UK training and assessment system would seriously discriminate against past, present and future generations of postgraduate UK trainees who have done so.

If the College feels the need to recognise psychiatrists who have not passed both parts of the Membership exam, it should ensure that there is some way to differentiate their title from that of those who have undergone the rigorous UK training.

Amit Malik Chair, CollegiateTrainees Committee, The Royal College of Psychiatrists, e-mail:doctmalik@hotmail.com

\section{Response of College}

The College has closed the category of Membership without examination on legal advice. The College wishes to make it possible for psychiatrists practising at consultant level in the UK or Ireland to become associated with the College at the earliest possible stage wherever they trained, qualified or gained experience. A consultation exercise is currently underway seeking the views of members 